ion source under construction for a cascade generator of $1.4 \mathrm{MeV}$. Mr. M. E. Reinders (Amsterdam) pointed out that in the Nier-type source used in his mass spectrometer the electron beam forms a potential trough which may prevent molecular ions escaping while atomic ions, formed with considerable kinetic energy, escape readily. Thus maximum currents of $\mathrm{H}^{+}$and $\mathrm{D}^{+}$are obtained with electron currents of 500 uamp., whereas the molecular ion currents of $\mathrm{H}_{2}{ }^{+}$and $\mathrm{HD}^{+}$are a maximum for currents of 1 ramp. This discrimination must be considered when, for example, the relative abundance of hydrogen and deuterium are being compared by the atomic ions. The difference in the nuclear separation of diatomic hydrogen and deuterium leads, on dissociation by electron bombardment, to different kinetic energies of the monatomic ions. The same afternoon the Laboratory for Mass Spectrography was visited, and the magnetic ion source of the Heil type was demonstrated. A $180^{\circ}$ isotope separator (100-cm. radius) is under construction.

On November 16, Dr. M. Hoyaux (Charleroi) read a paper on "Cyclotron Ion Sources". After reviewing the earlier types of sources, he discussed in some detail the physical and mathematical problems associated with the adaptation of the Von Ardennetype source for use in a cyclotron. Using as a basis the Broullin theory of the magnetron, he sketched the extension necessary to include the effect of gas collisions on the radial electron density and potential distribution. Theoretical work on the extraction mechanism is being pursued. Experiments at Charieroi on high-frequency ion sources for cyclotrons are due to begin.

The next speaker, Dr. J. Kistemaker (Amsterdam), discussed "Physical Problems in High-Intensity Ion Sources". He divided the subject into three main problems : (a) Production of jons in the discharge : for a given filament emission current, a maximum number of ions can be produced by choosing the correct accelerating voltage and increasing to a maximum the total electron path (for example, an oscillating electron source using an axial magnetic field). (b) Transport of ions to the exit opening: the potential distribution in the discharge must be such that the ions converge towards the exit opening and are drawn from a volume of intense ionization. (c) Extraction of ions : the ion currents are limited by space charge, and sufficient ions must drain towards the exit opening so that penetration of the extracting field into the discharge is not sufficient to extinguish it. Various questions of gas economy were discussed. An ion source has been constructed in which 50 per cent of the total flow through the exit opening are ions. At a gas pressure of $6 \times 10^{-5} \mathrm{~mm}$. of mercury and an extraction voltage of $8 \mathrm{kV}$., $6 \mathrm{~m}$.amp. of helium ions were measured passing through an exit $1 \mathrm{~cm}$. in diameter.

In the afternoon, Dr. C. Cassignol (Paris) discussed the "Extraction and Focusing of Ion Beams". He mentioned a promising type of magnetron ion source consisting of two short concentric cylinders in which the outer is the anode and the inner a perforated cathode. Due to the extended electron paths, intense ionization is produced at low pressures, and part of the ion current passes through the cathode and is extracted in an axial direction. Experimental results are not yet available. Some interesting information about the operation of the ion source in the Nier isotope separator was given by Dr. R. Bernas (Paris). He has observed that with increasing magnetic field the initial ion current ( 2 m.amp. focused beam) suddenly drops practically to zero while the probe and discharge current both increase. It is suggested that a sudden transition to a 'super state' completely altered the previous condition in this source, and the ion beam issuing from the exit slit was then widely divergent. Dr. P. M. Endt (Utrecht) then described some experiments on a pulsed Finkelstein source.

In the final talk of the session, Dr. H. Brinkman (Arnhem) suggested that very pure proton currents could be obtained by ionizing hydrogen in a tungsten cylinder maintained at $2,500^{\circ}$ C. At sufficiently low pressures, dissociation of molecular hydrogen is practically complete at this temperature. An anode placed in the tungsten cylinder serves to accelerate the electrons. The Conference was closed by a visit to the $30-\mathrm{MeV}$. synchro-cyclotron in the Institute of Nuclear Physics.

C. J. Zilverschoon

\section{EDUCATION IN BOLIVIA}

$\mathrm{A}^{\mathrm{N}}$ NOTHER of the series of basic studies on education in certain Central and South American countries has been prepared under the ægis of the United States Office of Education. The studies are part of a programme to promote understanding of educational conditions in the American countries and to encourage co-operation in the field of interAmerican education. Begun in 1943, the project involves travel by Office of Education specialists in the various countries to gather first-hand information on their educational systems and the preparation of reports from these data for publication. "Education in Bolivia" is based on data gathered by R. H. Nelson in Bolivia in 1947 and supplemented since then through documentation (Washington, D.C. : Government Printing Office).

Situated in the west-central region of South America, Bolivia is one of the two countries in the western hemisphere without a sea coast or sea port. Its area is estimated at half a million square miles, which is roughly ten times the size of England. Two principal mountain ranges cross the country from north-west to south-east. Between these ranges lies the High Plain, the largest and highest plateau in the western hemisphere. from which Bolivia gets the popular name of the "Land in the Sky". To the east, in the lowlands of the Amazon and Parana Plain, lies a tropical and sub-tropical section which comprises almost two-thirds of the total area of the Republic. In the highland plateau and the valleys leading eastwards from it are located the largest and most important cities of the Republic, La Paz, Cochabamba, Sucre, Potosi and Oruro.

The climate ranges from tropical heat in the eastern section to arctic cold in the mountains and high plains of the west. In the valleys to the east the climate is temperate. In both these regions the soil is largely poor and thin, but supports a meagre agriculture which supplies in part the needs of the peoples of these areas. In the eastern two-thirds of the country the possibilities of agricultural production are rich, although at present this area is sparsely populated and virtually undeveloped.

The 1,400 miles of railways in Bolivia form a system which connects the principal cities. Road and railway construction are enormously expensive in the rugged mountain areas, and a serious defect in the transportation is the lack of road and railway connexions with the eastern lowlands. Two principal 
airlines render efficient service among the main cities.

Tin is by far the leading export of Bolivia, which produces 15 per cent of the world's supply. Other metals exist in the mountains of the Republic and represent potential national wealth. The principal agricultural products include coca leaves from which cocaine is made, cinchona bark, rubber, animal products (hides and wool) and nuts. There is little or no manufacture in the country. Nothing is produced for export, and only a small amount for domestic consumption.

Under the constitution of 1938 the Republic of Bolivia has a representative government of three branches. The executive power is vested in a president, elected by direct suffrage for four years, and his appointed cabinet. The legislative division consists of a bicameral congress with a senate and chamber of deputies. All men of twenty-one years of age who can read and write are privileged to vote.

Of the estimated $3 \frac{1}{2}$ million people who make up the population of Bolivia, approximately $1 \frac{1}{2}$ million are Indian, 500,000 are white, principally of Spanish descent, and the remainder are of mixed blood. The Indians have good physique and constitute a great potential asset to their country if their social status could be improved through education and legislation. About 80 per cent of the population inhabit the highland one-third of the country's area and contribute to the mining industry. According to recent estimates, 75 per cent of the people of Bolivia are illiterate; most of these live in rural areas where schools are not available.

The recognized national religion is Roman Catholic; but other religions are permitted. Spanish is the national language; but the Aymara and Quechua tongues are spoken by most of the Indian and mestizo portions of the population.

Before the coming of the Spaniards in the sixteenth century, the culture of the Aymara and Quechua Indians was preserved and handed on from one generation to the next by word of mouth. To-day, public education in the elementary, secondary, rural, vocational and normal schools is under the administration and supervisory control of the Minister of Education, Fine Arts and Current Affairs. The great problem of Bolivian education lies in the relationship between the country's financial ability and the enormous need for increased educational facilities. In 1943 it was estimated that only 23.8 per cent of the 600,000 children of school age (7-14 years) were in daily attendance at school. While it is true that educational facilities have improved since 1943, even at a most generous estimate far less than half the nation's children attended any school at all in 1948 . The most hopeful aspect of this situation is the fact that the people of Bolivia are aware of the need for educational facilities and are making a progressive effort to find the solution to this problem.

In the rest of his report Nelson examines the different stages in Bolivian education in considerable detail ; the following features should be of special interest to educationists.

The problem of school attendance, especially in the elementary school, is serious owing to such factors as lack of transportation, illness, necessity for students to work and parental apathy or irresponsibility towards the question of schooling. Much is being done through the medium of parent-teacher groups to bring about a realization of the need for education of young children. These parent-teacher groups are also making a serious effort to combat the prevalent idea that education is not as necessary for girls as for boys.

The traditional method of instruction in Bolivian schools, as in schools of some other Latin-American republics, involves dictation of factual material by the teacher and transcription of this material verbatim by the student into a set of carefully kept notebooks. Recitation is formal and stereotyped, the student being expected to stand when called upon and repeat verbatim the dictated material requested ; free class discussion is not used as a method of instruction. The scarcity of text-books in Bolivian elementary schools is a serious handicap to teaching and especially to the teaching of reading.

Of the 309 urban elementary schools, thirty-four are night schools. A few of these are open to adults who wish to get an elementary education which they missed in their youth; but the large part of the nightschool student body is made up of children who work during the day. Some of those who work on farms come from distances of ten or fifteen miles.

The only requirement for admission to a secondary school beyond the usual proofs of good health and good character is the completion of the six-year elementary school course. Despite this, the secondary school enrolment of 14,821 students is less than 8 per cent of the total scliool enrolment. Tuition in the public secondary schools is free, and the instruction is much the same as in elementary schools. This has the sanction of long usage and is considered the most: practical method in view of the fact that almost no text-books or reference books are available.

Vocational education is a comparatively new development in Bolivian education, having first been introduced about 1942. Its inclusion in the school programme is thus still in an experimental stage. There are eight vocational schools for girls, seven industrial schools for boys and five commercial schools. In addition to these schools, four of the universities maintain institutes for certain types of technical training on the secondary level. These offer four years of training in mechanics, electricity, foundry and graphic arts. The stated object of the girls' vocational schools is to "complete the general education of women and to prepare them for the exercise of the manual occupations suitable to their sex".

Teacher training is carried out at various colleges, one of which, the National Teachers' School at Sucre, has operated continuously since its foundation in 1909. As part of the course in pedagogy and teaching methods, students are required to spend one hour per week during the third year of their course in observation of actual classroom teaching, and during the fourth year they are required to teach one hour a week for twenty-four weeks under the supervision of a methods instructor and a classroom teacher.

There are seven universities in Bolivia, all of which, as well as any which may later be created, constitute a national entity known as the Bolivian University. The aims and functions of the Bolivian University are as follows : "The Bolivian university will give impulse to the scientific investigation of university problems with the object of enriching the cultural patrimony of the university and it will especially undertake those national problems related to the development of the natural wealth of the country". As in other South American republics, the university congress includes student members.

T. H. HAWKINS 